Perinatology pISSN 2508-4887 • elSSN 2508-4895

\title{
Efficacy of Bakri Balloon Tamponade in Massive Postpartum Hemorrhage: A Series of 57 Cases
}

\begin{abstract}
Ha Yan Kwon, MD ${ }^{1,2}$, Young-Han Kim, MD, PhD 2,3, Yong-Won Park, MD, PhD ${ }^{4}$, Ja-Young Kwon, MD, PhD 2,3

'Department of Obstetrics and Gynecology, Dongguk University Ilsan Hospital, Goyang, ${ }^{2}$ Institute of Women's Life Medical Science, Yonsei University College of Medicine, Seoul, ${ }^{3}$ Division of Maternal Fetal Medicine, Department of Obstetrics and Gynecology, Severance Hospital, Seoul, ${ }^{4}$ Department of Obstetrics and Gynecology, Bundang Cheil Women's Hospital, Sungnam, Korea
\end{abstract}

Received: 22 August 2016 Revised: 20 October 2016 Accepted: 1 November 2016

Correspondence to Ja-Young Kwon, MD, PhD Division of Maternal Fetal Medicine, Department of Obstetrics and Gynecology, Severance Hospital, Institute of Women's Life Medical Science, Yonsei University College of Medicine, 50 Yonsei-ro, Seongsan-ro, Seodaemun-gu, Seoul 03722, Korea

Tel: $+82-2-2228-2230$

Fax: +82-2-313-8357

E-mail: jaykwon@yuhs.ac

Copyright@ 2016 by The Korean Society of Perinatology

This is an Open Access article distributed under the terms of the Creative Commons Attribution Non-Commercial License (http://creativecommons.org/license/ by-nc/4.0/), which permits unrestricted non-commercial use, distribution, and reproduction in any medium, provided that the original work is properly cited.
Purpose: To evaluate the efficacy of intrauterine Bakri balloon tamponade as a management of massive postpartum hemorrhage (PPH).

Methods: Retrospective study including women who underwent intrauterine Bakri balloon tamponade for massive PPH between April 2010 and July 2015 was conducted. Massive PPH was defined as estimated blood loss exceeding 1,500 mL. Bakri balloon was inserted into uterus if women had PPH despite medical treatment after vaginal delivery or cesarean section. The balloon was inflated with sterile saline and removed after 12-24 hours. Failure was defined as needing another procedure for hemorrhage control. Demographic, obstetric and specific factors in regard to the Bakri balloon use were recorded. The successful rate of hemostasis by Bakri balloon was evaluated.

Results: Among 138 women with PPH managed Bakri balloon insertion, 57 patients were diagnosed with massive PPH. The most common cause of massive PPH was placenta previa without accreta (54.4\%), uterine atony (33.3\%), placenta previa with accreta (10.5\%) and placenta accreta (1.8\%). The mean estimated blood loss was $2279.0 \mathrm{~mL}$ (range, 1,500-6,500 mL). The rate of successful control of massive PPH after Bakri balloon placement was $82.5 \%$. From the cases of 57 patients, 10 patients needed additional procedures; five required uterine artery embolization and five underwent cesarean hysterectomy. No short-term complications or maternal death were observed after Bakri balloon insertion.

Conclusion: Bakri balloon tamponade is an effective, simple and quick approach in the treatment of massive PPH and it is useful as complementary management for earning time for another procedure.

Key words: Bakri balloon, Massive postpartum hemorrhage, Intrauterine tamponade

\section{Introduction}

Postpartum hemorrhage (PPH) is a life-threatening complication in obstetrics and it is a major cause of maternal mortality worldwide. ${ }^{1} \mathrm{PPH}$ has been traditionally defined as an estimated blood loss of more than $500 \mathrm{~mL}$ after vaginal delivery or over 1,000 $\mathrm{mL}$ after cesarean section. Particularly if woman has massive PPH which is defined as bleeding exceeding $1,500 \mathrm{~mL}$ during delivery, patient may be in danger with needing massive transfusion, critical care and increasing the risk of death. ${ }^{2}$ The main causes of PPH are uterine atony, genital tract laceration, abnormal placentation, retained placental products and coagulation abnormalities, The management of PPH differs depending on these etiologies. The primary treatments for $\mathrm{PPH}$ include treatment of uterine atony with uterotonic agents, bimanual uterine massage and blood product replacement. If these conservative managements fail, surgical interventions must be considered. Surgical methods consist of ligation of uterine artery, intrauterine compression sutures and 
hysterectomy. Postpartum hysterectomy causes increased blood loss, injury to other organs and irreversible loss of fertility. Therefore, other nonsurgical conservative methods such as uterine artery embolization (UAE) or uterine balloon tamponade should be considered before hysterectomy.

Intrauterine balloon tamponade has been quite widely used as a second-line procedure in the management of $\mathrm{PPH}$. This tool acts to stop uterine bleeding via increasing intrauterine pressure over systemic pressure around the placental bed or low segment in placenta previa. ${ }^{3}$ Different balloons have been used such as the Sengstaken-Blakemore tube, Foley, Rusch or Bari balloon. The success rate for this technique has been reported by 60-90\%. ${ }^{4-7}$ Among these balloons, the Bakri balloon is specifically designed to fit into the uterine cavity, and it has been used popularly due to simple management and easy access.

This study describes the use of Bakri balloon for managing massive $\mathrm{PPH}$ that bleeding more than $1,500 \mathrm{~mL}$ after delivery. The aim of this study was to evaluate the success rate of Bakri balloon in cases of massive $\mathrm{PPH}$ that were intractable to medical treatment.

\section{Materials and methods}

This study was a retrospective review of patients diagnosed with massive PPH who failed conservative management with uterotonic agents and were subsequently treated with intrauterine balloon tamponade at one institute between April 2010 and July 2015. This study was approved by the Institutional Review Board of Severance Hospital. Medical records were reviewed to gather demographic, obstetric and specific factors involved in the use of balloon tamponade.

Massive PPH was defined as $>1,500 \mathrm{~mL}$ estimated blood loss after vaginal delivery or cesarean section. This was measured of the amount of bleeding before Bakri balloon insertion. The first standard managements for PPH such as uterine massage, bimanual compression, or medication with an intravenous infusion of Oxytocin (20-40 IU in 1,000 $\mathrm{ml}$ Ringer's lactate solution at a rate of $120 \mathrm{~mL} /$ hour) or an additional injection of intravenous Carbetocin were applied to all patients. Close inspection of the cervix and vagina was performed routinely for distinguishing genital tract lacerations in women with profuse bleeding after vaginal delivery. Any patients with bleeding who need surgical procedure after vaginal delivery due to lower genital tract lacerations were excluded. If the bleeding continued despite of primary medical treatments, the Bakri balloon catheter (Bakri SOS balloon; Cook ${ }^{\circledR}$ woman's Health, Spencer, IN, US) was applied.

The procedure for insertion of the Bakri balloon was similar to that originally described by the inventor. ${ }^{8}$ Following vaginal delivery, the Bakri balloon was inserted transvaginally under ultrasound guidance to confirm the correct positioning of the balloon. When the balloon was inserted during a cesarean section, the distal end of the catheter shaft was introduced into the uterine incision and passed through the cervix. After the balloon was inflated with approximately $100 \mathrm{~mL}$ of sterile saline solution, the lower segment incision was closed carefully in order to avoid damaging the balloon. Further filling was depending on the size and capacity of the uterus. Then, Betadine-soaked gauzes were packed into vagina to prevent slippage or prolapse of the balloon through the cervix. The distal end of the catheter was fixed to the patient's thigh and ultrasound visualization of balloon placement was confirmed after procedure. After Bakri balloon placement, the balloon drainage end was connected to a collecting bag to monitor blood loss. The balloon remained in place between 12 and 24 hours. Removal of the catheter was by either complete deflation after 24 hours or stepwise deflation by removing $50 \%$ of the fluid at 12 hours followed by complete deflation after 12 hours.

Bakri balloon tamponade was considered to be failed if the bleeding from drainage catheter was continued and more than $100 \mathrm{~mL}$ during 10 minutes, so further interventions such as UAE, compression sutures or hysterectomy were needed. Women were hospitalized either in postnatal word or intensive care in the postpartum period depending on the level of PPH and maternal tolerance. Pain was evaluated using the Wong-Baker Faces Pain Rating Scale (FPS) before removal of the balloon tube. FPS is a series of facial expressions to illustrate a spectrum of pain intensity. Research assistants pointed to each of the six faces and described each face using the brief word instructions pro- 
vided with the scale. Patients were asked to circle the face that best represented their level of pain severity. All patients had a Foley catheter for urine output monitoring and prophylactic broad-spectrum antibiotics were used. We compared between Bakri balloon success group and failure group to identify factors associated with its failure, as well as determine if any complications were associated with its use.

Outcome measures were compared with Student's $t$-test and chi-square analysis, as well as Fisher's exact test and Wilcoxon's test when appropriate due to smaller sample size. A $P$ value of 0.05 or below was considered statistically significant.

\section{Results}

During the study period, 138 women who were diagnosed with PPH following either vaginal delivery or cesarean section were managed with Bakri balloon. A total of 57 (41.3\%) of these women had massive PPH with an estimated blood loss exceeding 1,500 mL. All patients were diagnosed massive PPH and treated during hospital stay except one case. In one case, massive PPH was occurred 6 days after she was discharged from the hospital. She had cesarean section because of twin pregnancy. The mean age of these women were 34.2 years and 28 (49.1\%) were more than 35 years old. Of the women in whom the Bakri balloon was used for the management of massive PPH, twenty-three were nulliparous (40.4\%) and three (5.3\%) were multiple gestations (all were twin pregnancies). A total of 9 women (15.8\%) delivered vaginally and $48(84.2 \%)$ had a cesarean section. Out of 48 women with cesarean section, Bakri balloon was inserted during operation in 45 women, at recovery room in 2 women and at emergency room in one women who had massive bleeding after discharge from hospital. The mean gestational weeks at the time of delivery was 37.7 (range 34.28-40.71). Mean weight of newborn was 3,006.9 $\mathrm{g}$ and 4 babies were diagnosed with large for gestational age (Table 1).

As shown in Table 1, the leading cause of PPH was placenta previa without accreta in 31 cases (54.4\%), followed by uterine atony in 19 cases (33.3\%), placenta previa with accreta in 6 cases (10.5\%) and placenta accreta in 1 case
(1.8\%). The mean estimated blood loss was 2,279 mL (range 1,500-6,500 mL) before insertion of a Bakri balloon, and 20 patients had a massive bleeding more than $2,500 \mathrm{~mL}$. The mean volume of saline used to inflate balloon was 233.5 $\mathrm{mL}$ (range 50-700 mL). None of the patients had the Bakri

Table 1. Baseline and Pregnancy-Associated Characteristics of Women with Bakri Balloon Tamponade

\begin{tabular}{|c|c|}
\hline Characteristic & $\mathrm{N}=57(\%)$ \\
\hline Age, year (mean) & 34.2 (range 25-41) \\
\hline$\geq 35$ & $28(49.1)$ \\
\hline \multicolumn{2}{|l|}{ Parity } \\
\hline 0 & $23(40.4)$ \\
\hline 1 & $24(42.1)$ \\
\hline$\geq 2$ & $10(17.5)$ \\
\hline Multiple gestations & $3(5.3)$ \\
\hline \multicolumn{2}{|l|}{ Mode of delivery } \\
\hline Vaginal delivery & $9(15.8)$ \\
\hline \multicolumn{2}{|l|}{ Cesarean section } \\
\hline Elective & $34(59.6)$ \\
\hline Emergency & $14(24.6)$ \\
\hline Gestational age, weeks (mean) & 37.7 (range 34.28-40.71) \\
\hline Birthweight, g (mean) & 3,006.9 (range 1,790-3,990) \\
\hline LGA & $4(7.0)$ \\
\hline Blood loss, mL* (mean) & 2,279.0 (range 1,500-6,500) \\
\hline Volume of balloon inflation (mL) & 233.5 (range 50-700) \\
\hline Bakri balloon inflation time (hr) & 17.1 (range 0.2-36.1) \\
\hline \multicolumn{2}{|l|}{ Indication for Barki balloon tamponade } \\
\hline Uterine atony & $19(33.3)$ \\
\hline Placenta previa without placenta accreta & $31(54.4)$ \\
\hline Placenta previa with placenta accreta & $6(10.5)$ \\
\hline Placenta accreta & $1(1.8)$ \\
\hline Pain by FPS & 3.7 (range 1-8) \\
\hline ICU admission & $20(35.1)$ \\
\hline \multicolumn{2}{|l|}{ Hemoglobin/Hematocrit, mg/dL/\% (mean) } \\
\hline Antepartum & $\begin{array}{l}11.2 \text { (range 6.3-13.1)/ } \\
33.5 \text { (range 19.4-40.1) }\end{array}$ \\
\hline Postpartum $^{\dagger}$ & $\begin{array}{l}9.1 \text { (range 5.9-12.3)/ } \\
26.8 \text { (range 16.5-36.3) }\end{array}$ \\
\hline Day of postpartum admission, day (mean) & 4.8 (range 2-12) \\
\hline Maternal death & 0 \\
\hline
\end{tabular}

Values are presented as mean (range) or $\mathrm{n}(\%)$

Abbreviations: LGA, large for gestational age; ICU, intensive care unit.

*Blood loss before Bakri balloon insertion.

${ }^{\dagger}$ 48hours after delivery. 
balloon ruptured during and after inflation. The balloon was left in situ for 17.1 hours on average (range 0.2-36.1 hours). In 14 cases the balloon was in place less than 12 hours and in 9 cases more than 24 hours. Twenty patients were admitted to the intensive care unit for close monitoring. The mean pain score according to the FPS during Bakri balloon indwelling was 3.7 (range 1-8).

The Bakri balloon tamponade was effective in $82.5 \%$ of the included women. In 57 cases, 47 women were successfully managed with Bakri balloon and no further surgical interventions or UAE were needed. Ten of the 57 cases required additional treatment after failure of Bakri balloon tamponade management (Table 2). Two women who de- livered vaginally and three who delivered by cesarean section underwent UAE; five women who delivered by cesarean section underwent postpartum hysterectomy. In three cases of five patients with postpartum hysterectomy were diagnosed placenta accreta pathologically and in one case with UAE was suspected placenta accreta at the operation room.

Maternal demographics showed no significant differences between success group and failures, with maternal age, gestational age, delivery mode and infants with large for gestational age (Table 3). The cause of massive PPH was not predictive of failure. There was no difference in volume of balloon inflation between two groups. Outcomes in

Table 2. Additional Procedures Used in Eleven Cases with Bakri Balloon Tamponade Failure

\begin{tabular}{|c|c|c|c|c|c|c|c|}
\hline Case & Cause of PPH & $\begin{array}{l}\text { Mode of } \\
\text { delivery }\end{array}$ & $\begin{array}{c}\text { Gestational weeks } \\
\text { at delivery }\end{array}$ & Risk factors & Procedure & $\begin{array}{c}\text { Blood loss, } \\
\mathrm{mL}\end{array}$ & $\begin{array}{c}\text { Transfusion, } \\
\text { units }\end{array}$ \\
\hline 1 & Placenta previa and accreta & Elective CS & 37.71 & Placenta previa & Hysterectomy & 1,900 & $\begin{array}{l}21 \mathrm{PBCs} \\
4 \mathrm{FFP} \\
6 \text { Plt.conc }\end{array}$ \\
\hline 2 & Placenta previa & Elective CS & 37.57 & Placenta previa & Hysterectomy & 2,000 & $\begin{array}{l}6 \mathrm{PBCS} \\
1 \mathrm{FFP} \\
5 \text { Plt.conc }\end{array}$ \\
\hline 3 & Uterine atony & Elective CS & 37.14 & $\begin{array}{l}\text { Multiple pregnancy, } \\
\text { Placenta previa }\end{array}$ & UAE & 2,100 & $\begin{array}{l}11 \mathrm{PBCS} \\
3 \mathrm{FFP} \\
8 \text { Plt.conc }\end{array}$ \\
\hline 4 & Placenta previa and accreta & Elective CS & 37.86 & Placenta previa, two prior CS & Hysterectomy & 2,750 & $\begin{array}{l}24 \mathrm{PBCs} \\
4 \mathrm{FFP} \\
12 \text { Plt.conc }\end{array}$ \\
\hline 5 & Placenta previa and accreta & Elective CS & 38.14 & two prior curettages, placenta previa & UAE & 2,800 & $\begin{array}{l}10 \mathrm{PBCS} \\
5 \mathrm{FFP}\end{array}$ \\
\hline 6 & Placenta previa and accreta & Elective CS & 37.71 & Placenta previa & Hysterectomy & 3,000 & $\begin{array}{l}6 \mathrm{PBCS} \\
5 \mathrm{FFP} \\
6 \text { Plt.conc }\end{array}$ \\
\hline 7 & Uterine atony & VD & 37.28 & & UAE & 3,100 & $\begin{array}{l}14 \mathrm{PBCS} \\
5 \mathrm{FFP}\end{array}$ \\
\hline 8 & Uterine atony & VD & 40.14 & Large fetus & UAE & 3,800 & $\begin{array}{l}28 \mathrm{PBCs} \\
6 \mathrm{FFP} \\
16 \text { Plt.conc }\end{array}$ \\
\hline 9 & Placenta previa & Emergency CS & 37.14 & Placenta previa & UAE & 2,300 & $\begin{array}{l}13 \text { PBCs } \\
3 \text { FFP } \\
12 \text { Plt.conc }\end{array}$ \\
\hline 10 & Uterine atony & Elective CS & 38.28 & Placenta previa & Hysterectomy & 3,500 & $\begin{array}{l}10 \mathrm{PBCs} \\
2 \mathrm{FFP} \\
12 \text { Plt.conc }\end{array}$ \\
\hline
\end{tabular}

Abbreviations: VD, vaginal delivery; CS, cesarean section; UAE, uterine artery embolization; PBC, packed blood cell; FFP, fresh frozen plasma; Plt.conc, Platelet concentrate. 
Table 3. Maternal Demographics and Outcomes between Success and Failure Group with Bakri Balloon Management

\begin{tabular}{|c|c|c|c|}
\hline & Success $(n=47)$ & Failure $(n=10)$ & $P$ value \\
\hline Maternal age, yr & 33.9 (range, 25-41) & 35.3 (range, 31-39) & 0.32 \\
\hline AMA & $22(46.8)$ & $6(60.0)$ & 0.50 \\
\hline Delivery mode & & & 0.65 \\
\hline Vaginal delivery & $7(14.9)$ & $2(20.0)$ & \\
\hline LGA & $4(8.5)$ & $1(11.1)$ & 0.17 \\
\hline Cause of PPH & & & 0.25 \\
\hline Uterine atony & $15(31.9)$ & $4(40.0)$ & \\
\hline Placenta previa without accreta & $28(59.6)$ & $3(30.0)$ & \\
\hline Placenta previa with accreta & $3(6.4)$ & $3(30.0)$ & \\
\hline Time between bleeding/balloon insertion (min) & 48.1 (range, 2-350) & 76.0 (range, 2-258) & 0.44 \\
\hline Bakri balloon indwelling time (hr) & 19.5 (range, 1.0-36.0) & 5.0 (range, $0.16-27.0$ ) & $<0.01$ \\
\hline Drained blood loss after Bakri insertion & & & $<0.01$ \\
\hline Total & 155.1 (range,0-560) & 811.1 (range, 400-1200) & \\
\hline Per 1 hour & 24.7 (range, $0-400$ ) & 440.2 (range, 31.48-1195.6) & \\
\hline Blood loss* & 2184.1 (range, 1500-6500) & 2725.0 (range, 1900-3800) & $<0.01$ \\
\hline Length of hospitalization & 4.3 & 7.2 & $<0.01$ \\
\hline ICU admissions & $10(21.3)$ & $10(100.0)$ & $<0.01$ \\
\hline Transfusion & $40(85.1)$ & $10(100.0)$ & 0.19 \\
\hline
\end{tabular}

Values are presented as mean (range) or $\mathrm{n}(\%)$.

Abbreviations: AMA, advanced maternal age (>35yr); GA, gestational age; LGA, large for gestational age; PPH, postpartum hemorrhage; ICU, intensive care unit *Blood loss before bakri balloon insertion.

the failure group were notable for longer length of hospitalization, higher likelihood of ICU admission, and higher transfusion rate. The drained blood loss after Bakri insertion and average blood loss per 1 hour were heavier in the failure group compared to those of success group.

No cases of hypoxic encephalopathy or death were encountered and no complications were observed due to insertion of Bakri balloon such as uterine rupture, endometritis and uterine incision dehiscence.

\section{Discussion}

The incidence of PPH is steadily rising in association with an increased incidence of cesarean section with abnormal placentation, increased rates of maternal obesity and rising frequency of multiple pregnancies by artificial reproductive technologies. ${ }^{10} \mathrm{PPH}$ is a significant cause of maternal morbidity and mortality. Especially if massive, women suffer from acute renal necrosis, irreversible hypovolemic shock, disseminated intravascular coagulation, Sheehan's syndrome until the death of the patient and death as well as severe anemia with the need for massive transfusion. ${ }^{2}$ Because late diagnosis and delayed management contribute to increased maternal morbidity when women had a massive PPH, rapid decision and interventions are essential. As a treatment for $\mathrm{PPH}$, intrauterine balloon tamponade does not require either a highly technological facility or technical skill so that it can 
Table 4. Studies Reporting Uterine Balloon Tamponade Results with Severe postpartum hemorrhage

\begin{tabular}{|c|c|c|c|c|c|c|c|}
\hline Authors & Year & Balloon type & Mean blood loss (mL) & No. of cases & No. of successful cases & Success rate (\%) & Postpartum hysterectomy \\
\hline Majumdar A et al. ${ }^{12}$ & 2010 & Rusch & 2,450 & 22 & 13 & 59.1 & 7 \\
\hline Gronvall M et al. ${ }^{14}$ & 2012 & Bakri & 4,812 & 44 & 37 & 84.0 & 4 \\
\hline Chan LL et al. ${ }^{11}$ & 2013 & SB & 2,000 & 11 & 9 & 81.8 & 2 \\
\hline Ferranzzani S, et al. ${ }^{13}$ & 2014 & Rusch & 1,759 & 52 & 39 & 75.0 & 10 \\
\hline Total & & & & 210 & 171 & 81.4 & \\
\hline
\end{tabular}

Abbreviation: SB, Sengstaken-Blakemore tubes.

be rapidly applied for hemostasis. This procedure is the least invasive and lower-cost approach and it can preserve fertility by preventing hysterectomy.

The overall success rate of Bakri balloon in our study was $82.5 \%$ which is comparable to previous studies. However, only few case series regarding outcomes using intrauterine balloon tamponade for massive PPH have been reported previously (Table 4). A series of 11 cases using SengstakenBlakemore tubes was published, in which mean blood loss was $2000 \mathrm{ml}$ and $81.8 \%$ success rate. In another study using the Rusch balloon, the success rate 59.1\% (13/22 cases) and seven patients need hysterectomy. ${ }^{12}$ Ferranzzani and colleagues reported that the Rusch balloon was successful in 39 of the 52 cases $(75.0 \%)$ without using other procedure for treatment of $\mathrm{PPH}^{13}$ For the Bakri balloon, the rate of success varies from $84 \%$ (37/44 cases) in the study by Gronvall et al., ${ }^{14}$ to $60 \%$ in that by Diemert et al. ${ }^{15}$ (12/20 cases), to $88 \%$ $\left(55 / 61\right.$ cases) in the study by Alouini et al. ${ }^{16}$ In agreement with other studies, intrauterine balloon tamponade is effective for PPH even if massive bleeding during delivery.

In our study, both total drained blood loss and blood loss per hour after Bakri insertion were significant higher in failure group compared of those in success group, suggesting that another procedure such as UAE or hysterectomy should be considered when bleeding passed through drainage tube was over $400 \mathrm{~mL}$ within 1 hour. As continued bleeding after balloon insertion represent balloon management failure, the Bakri balloon can make a rapid decision for another procedures such as UAE or surgical procedure when persisting bleeding was observed by connected tube. Although many series about the successful use of different types of balloon tamponades such as the Foley catheters, Sengstaken-Blakemore tubes and Rusch balloon catheters, these have many shortcomings. ${ }^{17}$ The balloon capacity of the Foley catheter is too small to result in satisfactory compression of the uterus. The Sengstaken-Blakemore tube was originally designed for upper gastrointestinal tract bleeding. Thus, it does not conform to the shape of the uterus, and multiple ports often confuse the user at times of emergent use. As for the Rusch balloon catheter, there is a tendency to miss concealed hemorrhages due to the absence of a drainage port. The Bakri balloon catheter has been able to overcome these aforementioned limitations. This catheter was specifically designed to fit into the uterine cavity and is equipped with a drainage port for ongoing blood loss.

The original Bakri balloon was used for low-lying placenta/placenta previa ${ }^{8}$ and the Royal College of Obstetricians and Gynaecologists (RCOG) guidelines of 2011 considered the intrauterine balloon for management of massive hemorrhage with placenta previa and accreta. ${ }^{18}$ In our study, the success rate of the use of Bakri balloon in massive PPH with placenta previa was $83.7 \%$ (31/37). If we consider that study group consisted of women with placenta previa without accreta, then our study showed a 90.3\% success rate (28/31). Placenta previa and accreta are becoming more frequent as increasing rate of cesarean section and the association of uterine atony with abnormal placentation seems to be related with higher blood loss and more transfusions. For these reasons, we suggest the Bakri balloon as an alternative treatment, which can be used to resolve massive PPH in cases of abnormal insertion of the placenta and before more invasive procedures. 
Among the 57 cases examined, ten required additional treatment after Bakri balloon tamponade. In five failed cases in the cesarean section group who later underwent hysterectomy, three had placenta previa with accreta. In one cases with cesarean section who had a successful Bakri balloon catheter placement during cesarean section for $\mathrm{PPH}$ due to placenta previa, massive rebleeding was noted in the recovery room caused by complete displacement of the balloon into the vaginal cavity. At the time of balloon placement, the cervix was dilated to $1 \mathrm{~cm}$ but firm; therefore, vaginal gauze packing was not performed. However, results of a pelvic exam following balloon displacement showed that the cervix was dilated to 5-6 cm and 50\% effaced. This finding led us to believe that the inflated balloon functioned as a transcervical catheter that mechanically dilated the cervix and a lack of balloon support (vaginal packing) contributed to balloon expulsion. Thus, we strongly recommend vaginal packing for balloon support and checking the balloon position by ultrasound at the end of surgery to prevent treatment failure due to balloon displacement.

A strength of our study is that we evaluated the effectiveness of Bakri balloon particularly in massive bleeding among larger sample compared to previous studies since Bakri had been introduced. Among PPH patients, we analyzed women with estimated blood loss more than 1,500 mL. Our study also had homogeneity. All procedures were conducted by four obstetricians and the physician filled in the standardized Bakri insertion and removal records including causes of $\mathrm{PPH}$, inflation volume of balloon, time of insertion and removal and pain score. The major limitation of our study is the restrospective design that was restricted to evaluate complications or long term fertility. Another limitation is that there could have been a selection bias due to incomplete data in some of factors. In addition, women who underwent UAE or surgical procedure without trying to insert Bakri balloon were excluded in this study. It may affect to be overestimated the success rate of Bakri balloon in massive PPH. However, Bakri balloon could reduce heavy bleeding pending the arrangement of other procedures and this also regard efficiency of Bakri balloon to control massive $\mathrm{PPH}$.

Intrauterine Bakri balloon tamponade is an effective tool with a comparable success rate to other treatment modalities for managing massive PPH when standard uterotonic agents fail. Considering its merits over other balloon catheters as well as its cost-effectiveness and lower invasiveness compared to uterine artery embolization and hysterectomy, uterine balloon tamponade using the Bakri balloon catheter deserves to be the first choice among second-line therapies for patients with massive PPH who are unresponsive to uterotonic agents. In patients who were delivered by cesarean section for placenta previa/accreta, intrauterine Bakri balloon combined with hemostatic compression sutures could further enhance success rates and preserve fertility. Bakri balloon tamponade can be also used not only in tertiary centers but also in limited-resource centers, and it may be able to earn time to prepare another procedure with preventing massive bleeding or refer patient to another hospital.

\section{References}

1) Khan KS, Wojdyla D, Say L, Gülmezoglu AM, Van look PF. WHO analysis of causes of maternal death: systematic review. Lancet 2006;367:106674

2) Bonnar J. Massive obstetric hemorrhage. Baillieres Best Pract Res Clin Obstet Gynaecol 2000;14:1-18.

3) Condous GS, Arulkumaran S. Medical and conservative surgical management of postpartum hemorrhage. J Obstet Gynaecol Can 2003;25: 931-6.

4) Dabelea V, Schultze PM, McDuffie RS. Intrauterine balloon tamponade in the management of postpartum hemorrhage. Am J Perinatol 2007; 24:359-64

5) Seror J, Allouche C, Elhaik S. Use of Sengstaken-Blakemore tube in massive postpartum hemorrhage: a series of 17 cases. Acta Obstet Gynecol Scand 2005;84:660-4.

6) Keriakos R, Mukhopadhyay A. The use of the Rusch balloon for management of severe postpartum haemorrhage. J Obstet Gynaecol 2006; 26:335-8.

7) Akhter S, Begum MR, Kabir Z, Rashid M, Laila TR, Zabeen F. Use of a condom to control massive postpartum hemorrhage. MedGenMed 2003;5:38-43.

8) Bakri YN, Amri A, Abdul Jabbar F. Tamponade-balloon for obstetrical bleeding. Int J Gynaecol Obstet 2001;74:139-42.

9) Hockenberry MJ, Wilson D. Wong's Essentials of Pediatric Nursing. 9th ed. St Louis: Elsevier Inc, 2013:149-50.

10) Knight M, Callaghan WM, Berg C, Alexander S, Bouvier-Colle M-H, Ford $J B$, et al. Trends in postpartum hemorrhage in high resource countries: a review and recommendations from the International Postpartum Hemorrhage Collaborative Group. BMC Pregnancy Childbirth 2009;9:55. 
11) Cahn LL, Lo TK, Lau WL, Lau S, Law B, Tsang HH, Leung WC. Use of second-line therapies for management of massive primary postpartum hemorrhage. Int J Gynaecol Obstet 2013;122:238-43.

12) Majumdar A, Saleh S, Davis M, Hassan I, Thompson PJ. Use of balloon catheter tamponade for massive postpartum haemorrhage. J Obstet Gynaecol 2010;30:586-93.

13) Ferrazzani S, ladarola R, Perrelli A, Botta A, Moresi S, Salvi S, et al. Use of an intrauterine inflated catheter balloon in massive post-partum hemorrhage: a series of 52 cases. J Obstet Gynaecol Res 2014;40:1603-10.

14) Grönvall M1, Tikkanen M, Tallberg E, Paavonen J, Stefanovic V. Use of Bakri balloon tamponade in the treatment of postpartum hemorrhage: a series of 50 cases from a tertiary teaching hospital. Acta Obstet Gyne- col Scand 2013;92:433-8.

15) Diemert A, Ortmeyer G, Hollwitz B, Lots M, Somville T, Glosemeyer P, et al. The combination of intrauterine balloon tamponade and the $B$ Lynch procedure for the treatment of severe postpartum hemorrhage. Am J Obstet Gynecol 2012;206:e1-4.

16) Alouini S. Bakri balloon tamponade as first step to manage severe postpartum haemorrhage. Ir J Med Sci 2014;183:693.

17) Georgiou C. Balloon tamponade in the management of postpartum haemorrhage: a review. BJOG 2009;116:748-57.

18) Gynaecologists, L.R.C.o.O.a., RCOG Placenta Praevia, Placenta Praevia Accrete and Vasa Praevia: Diagnosis and Management (Green-top Guideline No.27). 